\title{
Vizinhança Sustentável: avaliação da Sustentabilidade da Ilha Palm Jumeirah em Dubai
}

\author{
Sustainable Neighborhood: Sustainability Evaluation of Palm \\ Jumeirah Island in Dubai
}

\section{Barrio Sostenible: Evaluación de la Sostenibilidad de la isla Palm Jumeirah en Dubái}

\author{
ALI, Khuloud ${ }^{1}$ \\ VASCONCELLOS, Virgínia Maria Nogueira de ${ }^{2}$ \\ 1 Programa de Pós-Graduação em Arquitetura, Faculdade de Arquitetura e Urbanismo, Universidade federal do \\ Rio de Janeiro, PROARQ-FAU-UFRJ, Rio de Janeiro - RJ, Brasil. claudia.taylor.br@gmail.com \\ ORCID: 0000-0002-8908-353X \\ 2 Programa de Pós-Graduação em Arquitetura, Faculdade de Arquitetura e Urbanismo, Universidade federal do \\ Rio de Janeiro, PROARQ-FAU-UFRJ, Rio de Janeiro - RJ, Brasil. virginia.vasconcellos@gmail.com \\ ORCID: 0000-0003-0740-8474




\title{
Resumo
}

Os Emirados Árabes Unidos passaram as últimas duas décadas trabalhando para transformar seu litoral, ampliando seu espaço físico e criando paisagens como as ilhas artificiais. O intuito era mudar sua economia, antes baseada no petróleo, para uma economia de serviços e turismo. A rápida expansão do solo urbano acarretou sérios desafios para a sustentabilidade do país. Este artigo, que tem a ilha artificial Palm Jumeirah como exemplo, objetiva estudar o desenho, a construção da ilha e sua relação com a sustentabilidade. Começar-se-á com uma revisão da literatura que identifica as terminologias relacionadas a Vizinhanças Sustentáveis (VS), conforme estabelecido pela ONU. Segue-se para uma análise de estudo de caso, com pesquisa de campo e aplicação dos cinco princípios de VS nas Palm Islands, em Dubai, para entender e explorar o conceito de sustentabilidade no local. Os resultados mostraram que as intervenções feitas em Dubai, como a ilha Palm Jumeirah, deram origem a melhorias significativas para a economia (como desejado), mas geraram conflitos socioculturais, além de problemas ambientais, principalmente ao ambiente marinho.

Palavras-Chave: Ilhas artificiais; Vizinhanças Sustentáveis; Sustentabilidade; Qualidade ambiental; Impactos sociais; Ilha Palm Jumeirah, Dubai.

\begin{abstract}
The United Arab Emirates has spent the last two decades working to transform its coastline, expanding its physical space and creating monumental artificial landscapes like the artificial islands, to shift its oil-based economy to a service and tourism economy. The rapid expansion of urban land cover has posed serious challenges for the sustainability of the country. This article, which has the Palm Jumeirah Island as an example, aims to study the design, construction of the islands and their relation to sustainability. The research will start with a literature review that identifies all related terminologies to Sustainable Neighborhoods (SN). A case study analysis will be done including; site visit, and applying the five principles of SN on the Palm island in Dubai to understand and explore the sustainability principles in it. The results showed that interventions in Dubai, such as Palm Jumeirah Island, led to significant improvements to the economy (as desired), but generated sociocultural conflicts as well as environmental problems, especially in the maritime environment.
\end{abstract}

Key-Words: Artificial islands; Sustainable neighborhood; Sustainability; Environmental quality; Social impacts; Palm Jumeirah Island; Dubai.

\section{Resumen}

Los Emiratos Árabes han pasado las últimas dos décadas trabajando en cambiar su litoral, ampliando su espacio físico y creando paisajes como las islas artificiales. El objetivo era cambiar su economía, antes basada en el petróleo, a una economía de servicios y turismo. El desarrollo rápido del suelo urbano ocasionó serios retos para la sostenibilidad del país. Este artículo, que tiene la isla artificial Palm Jumeirah como ejemplo, tiene como finalidad estudiar el diseño, la construcción de la isla y su relación con la sostenibilidad. Se empezará por la revisión de la literatura que identifica los términos relacionados a Barrios Sostenibles (BS), de acuerdo con lo establecido por la ONU. Seguido de un análisis de estudio de caso, con investigación de campo y aplicación de los cinco principios de BS en las islas Palm, en Dubái, para entender y explotar el concepto de sostenibilidad en el lugar. Los resultados indican que las intervenciones hechas en Dubái, como las islas Palm Jumeirah, originaron las mejorías significativas para la economía (como se deseado), pero generaron conflictos socioculturales, además de problemas ambientales, principalmente al ambiente marino.

Palabras Claves: Islas artificiales; Barrios Sostenibles; Sostenibilidad; Calidad Ambiental; Impactos sociales; Isla Palm Jumeirah; Dubái. 


\section{Introdução}

Nos últimos anos, o mundo se urbanizou aceleradamente e, pela primeira vez, em 2008, a população urbana excedeu a rural. Até 2050, espera-se que dois terços das pessoas morem em áreas urbanas. Como resultado dessa migração mundial, as Vizinhanças Sustentáveis surgem como uma alternativa significativa em direção ao desenvolvimento sustentável. O conceito foi adotado pela Organização Mundial das Nações Unidas - ONU, evocando o décimo primeiro Objetivo de Desenvolvimento Sustentável, que destaca a importância de "tornar cidades e assentamentos humanos inclusivos, seguros, resilientes e sustentáveis" (ONU, 2014; GILDROY et al., 2008; AL-HAGLA, 2008).

Este artigo aborda as questões ligadas à formação de vizinhanças sustentáveis na llha Palm Jumeirah, em Dubai, Emirados Árabes. Os Emirados Árabes Unidos (EAU) são constituídos por seis pequenos estados chefiados por um Emir, além do principal - Dubai -, totalizando sete regiões (figura 1). Estas áreas foram reunidas como um Estado Federal, em 1971 (AL-ULAMA, 1994). Dubai é o segundo maior emirado e está localizado na Costa do Golfo Pérsico.

Figura 1: Divisão dos Emirados Árabes

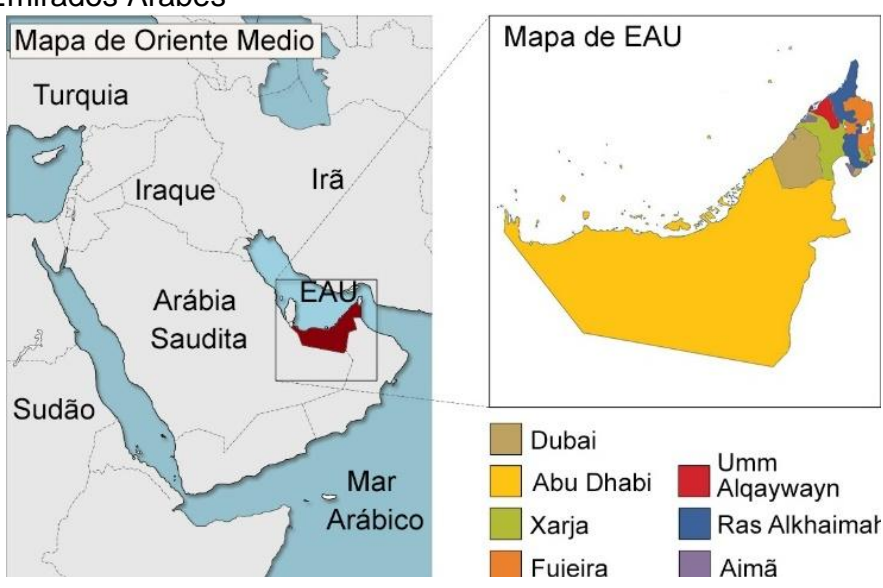

Fonte: Autor, baseado no Google Maps, 20019

Mais de duzentas nacionalidades vivem e trabalham em Dubai, tornando-a uma das principais cidades do mundo em números de imigração. De acordo com o World Migration Report 2015, "em muitas dessas cidades, como Sydney, Londres e Nova York, os migrantes representam mais de um terço da população e, em algumas cidades como Bruxelas e Dubai, os migrantes respondem por mais da metade da população" (LEE, 2015). Dubai é composta por $83 \%$ de imigrantes, sobressaindo-se às demais.

Com forte proposta de alcançar alto nível de desenvolvimento econômico, os governantes de Dubai vêm se esforçando para torná-la uma cidade integrada ao chamado "mundo globalizado", buscando,-novas formas de crescimento econômico, para vencer os problemas oriundos da escassez de petróleo (que era sua principal e forte fonte de renda). Os governantes, então, passaram a investir recursos na construção de megaprojetos arquitetônicos voltados ao turismo e à

\footnotetext{
${ }^{1}$ Segundo Sassen (2009 apud SANTOS, 2016), para a socióloga Sassen, a cidade global constitui um o espaço estratégico para grupos e indivíduos das mais variadas origens, no qual essa diversidade se aglutina em dois grandes âmbitos: a do capital globalizado e a dos menos favorecidos da sociedade.
} 
habitação de alto padrão construtivo (ALAWADI, 2013). Além disso, devido à escassez de terras, muitas áreas foram criadas a partir de aterros no mar e avanços para solos desérticos $A$ criação das ilhas artificias para uso residencial e comercial voltadas ao turismo surge, assim, como solução para o crescimento do setor econômico. Além de suas grandes dimensões, as ilhas chamam a atenção por seus desenhos em forma de palmeiras e mapas.

Com isso, Dubai desponta como uma grande potência da construção civil e, sobretudo do setor imobiliário, onde novas técnicas e materiais proporcionaram o surgimento das ilhas e edifícios cada vez mais altos, com desenhos arrojados e que referenciam o lugar como espaço de riqueza e poder (GIBLING, 2013), como, exemplificativamente, Burj Khalifa, Burj Al Arab, Dubai Marina e as Palm Islands. As formas, tanto das edificações quanto das ilhas, foram divulgadas no mundo inteiro, colocando-as como importante centro de interesse de turismo e pesquisa. Nelas, foram implantadas as atividades, habitações e unidades hoteleiras para incrementar o turismo e o crescimento da economia. No entanto, a região enfrenta alguns problemas decorrentes deste processo. Atualmente, por exemplo, Dubai enfrenta muitas críticas de ambientalistas, que apontam que a construção das ilhas destrói os recifes de corais, causando mudanças nas correntes marítimas naturais, e que o formato delas afeta diretamente o planejamento urbano acima da superfície. Outro fator de críticas é que Dubai buscou resolver os desafios econômicos ao estabelecer políticas que são adequadas à população mais abastada e à economia do país, com o incentivo à compra de imóveis por estrangeiros de alta renda, gerando empregos e arrecadação de impostos. Porém, não resolveu problemas como a distribuição de renda, aumentando a desigualdade socioeconômica local, onde se sobressai a precariedade do trabalho dos imigrantes, sobretudo aqueles que ajudaram a construir a região (SÖNMEZ et al., 2011).

Os principais objetivos deste artigo são: compreender o significado e o contexto da sustentabilidade em vizinhanças sustentáveis, explicar a proposta A New Strategy of Sustainable Neighborhood Planning, da ONU-Habitat, aplicando os cinco princípios de VS à ilha artificial Palm Jumeirah, em Dubai, para analisá-las frente a questões de sustentabilidade.

\section{Metodologia}

Aproveitou-se a estadia de seis anos em Dubai para assinalar as observações realizadas na ilha neste período, a fim de compor o estudo. Contando com observação direta não participativa, ele priorizou registros fotográficos e documentos oficiais, como mapas locais, com o objetivo de registrar as áreas de uso e verificar a distribuição populacional e seu funcionamento. Como primeiro passo, no entanto, foi realizada uma pesquisa bibliográfica sobre o significado e contexto da sustentabilidade, para conceituar "vizinhança sustentável" e apresentar a região de Dubai, destacando sua localização, desenvolvimento e composição atual de sua sociedade e valores culturais.

O trabalho contempla um estudo de caso, com combinação de técnicas qualitativas e quantitativas. A abordagem qualitativa foi realizada a partir de observação direta não participativa, para entender o cenário atual da região, o grupo de indivíduos e as formas de comportamento humano analisados. A abordagem quantitativa aplica os cinco princípios de vizinhanças sustentáveis, definidos pela ONU-Habitat (2014), ao estudo, usando mapas da ferramenta Google Earth e dados obtidos nos levantamentos de campo, realizados ao longo de um ano.

Tais visitas incluíram observações e levantamentos físicos das diferentes áreas de uso do solo: 
edifícios residenciais uni e multifamiliares, áreas comerciais e de serviços, espaços públicos e de circulação (pedestres e veículos). As medições objetivaram coletar informações sobre o zoneamento e suas áreas correspondentes e foram realizadas com trenas digitais. Foi realizada, ainda, uma visita ao acampamento dos trabalhadores imigrantes, localizado em Al Rashidiya, na rua 12, para observar a qualidade de vida de um grupo de trabalhadores na ilha.

A análise da ilha foi, portanto, realizada a partir de levantamentos bibliográficos e da vivência de seis anos do pesquisador. A análise dos três princípios da sustentabilidade foi realizada com base na revisão bibliográfica e dos cinco princípios de vizinhanças sustentáveis, definidos pela ONUHabitat (2014), com base nos levantamentos físicos de campo e nas observações diretas não participativas. Desta forma, este trabalho busca se destacar dos demais estudos realizados por ser atual e trazer o olhar de quem vivenciou a área e ainda mantém laços com o local.

\section{Fundamentação Teórica}

O conceito de sustentabilidade reflete formas de se investir na minimização dos problemas decorrentes da falta de planejamentos integrados que preservem os recursos naturais, protejam a sociedade, ao mesmo tempo, preservem e estimulem o crescimento e o desenvolvimento econômicos. Com isso, aborda como a escassez de recursos naturais, desde a Antiguidade, consolida-se em toda a cultura humana em busca da utilização desses recursos contínua e perpetuamente. Tal pensamento contribui para a afirmação de Grober (2007) acerca de tomar as questões referentes à sustentabilidade não como um movimento ambiental moderno, mas como uma maneira de pensar e agir enraizada nas culturas das sociedades, que amadureceu ao longo de três séculos. Jabareen (2008) enfatiza que a proteção das questões ambientais, sociais e econômicas deve integrar o processo de desenvolvimento sustentável. Segundo Tom Kuhlman e John Farrington, o desenvolvimento pode ser considerado uma abordagem multidimensional que busca uma maior qualidade de vida para todos (KUHLMAN; FARRINGTON, 2010). Se o desenvolvimento sustentável deseja prosperar, deve atrair pessoas e se refletir no comportamento de seus usuários, para manter e respeitar seus valores sociais. (PACKAL'EM, 2010; NURSE, 2006; DUXBURY, 2001).

O conceito de vizinhança sustentável trata a integração de perspectivas locais, regionais e globais, mantendo, ao mesmo tempo, as perspectivas sociais, econômicas e ambientais em um nível sustentável, por meio de visões de longo prazo e ações de curto prazo (BIJOUX, 2012). Ercan e Ozden (2014) afirmam que o conceito de vizinhança sustentável é bastante tangível para os indivíduos, pois eles podem ver e sentir o ambiente e a comunidade em seu interior. Um bairro sustentável deve oferecer um ambiente físico de qualidade que incorpore fortes redes socioculturais (ERCAN; OZDEN, 2014). Os aspectos ambiental, econômico e social são os princípios fundamentais do desenvolvimento de Vizinhanças Sustentáveis (EMAS, 2015).

A ONU-Habitat (2014) estabeleceu uma nova abordagem que aprimora as teorias atuais de planejamento urbano sustentável para ajudar a desenvolver uma interrelação viável entre moradores e espaço urbano e aumentar o valor da terra. Ela se baseia em cinco princípios que apoiam as três características principais de vizinhanças e cidades sustentáveis: compacto, integrado e conectado. São eles:

1- Criação de espaço adequado e uma rede eficiente de ruas - a rede deve ocupar pelo menos $30 \%$ da terra e pelo menos $18 \mathrm{~km}$ de extensão por $\mathrm{km} 2$. A malha deve diferir da prática 
moderna nos seguintes aspectos: ruas passíveis de pedestres e ciclistas; incentivo ao transporte público; hierarquia de estradas altamente interconectada; e espaço de estacionamento suficiente;

2- Proporcionar alta densidade - abrigar, pelo menos, 15.000 pessoas por km2, para responder diretamente à explosão da população global e à rápida urbanização. O objetivo deste princípio é promover o crescimento urbano de alta densidade, mitigar a expansão urbana e aumentar a eficiência da terra;

3 - No uso misto da terra, pelo menos $40 \%$ do solo, deve ser alocado para uso econômico em qualquer vizinhança. O objetivo é desenvolver uma gama de atividades compatíveis e o uso da terra em locais adequados para fornecer empregos locais, incentivar a economia local, minimizar a dependência de carros, incentivar o tráfego de pedestres e ciclistas e prestar serviços públicos mais próximos;

4- Promover a miscigenação social, fornecendo casas de diferentes faixas de preços para acomodar vários níveis de renda. De $20 \%$ a $50 \%$ da área total do território residencial deve ser de baixo custo. Além disso, cada tipo de posse não deve exceder $50 \%$ do total. O mix social fornece a base para que as redes sociais sejam saudáveis, o que, por sua vez, é a força motriz da vida da cidade; e

5- Promover a especialização limitada no uso do solo urbano, objetivando limitar o uso único de quarteirões ou vizinhanças. Os blocos únicos não devem exceder $10 \%$ de qualquer vizinhança. O princípio 5 visa a ajustar/limitar o uso de zoneamento funcional para implementar políticas mistas de uso da terra e se concentra no aspecto do uso da terra.

A ONU estabelece ainda, as áreas para aplicação dos princípios:

- Cidades em rápido crescimento, para ajudar no fornecimento de infraestrutura, terrenos e serviços públicos. Ressalta-se que o rápido crescimento da população pode advir de crescimento natural, imigração rural em busca de emprego, entre outros;

- Novos assentamentos urbanos e extensões urbanas, para evitar repetir erros do passado;

- Declínio das cidades, para iniciativas de revitalização e transformação urbana;

- Cidades em crescimento que não têm terra para extensão adicional podem usar os cinco princípios para alcançar um processo de densificação mais suave (ONU-Habitat, 2014).

A figura 2 apresenta as medidas traçadas pela ONU-Habitat, nas quais os dados da vizinhança são agrupados e permitem sua quantificação e visualização (ONU-Habitat, 2014). 
Figura 2: Análise de sustentabilidade de vizinhanças baseada nos cinco princípios da ONU-Habitat

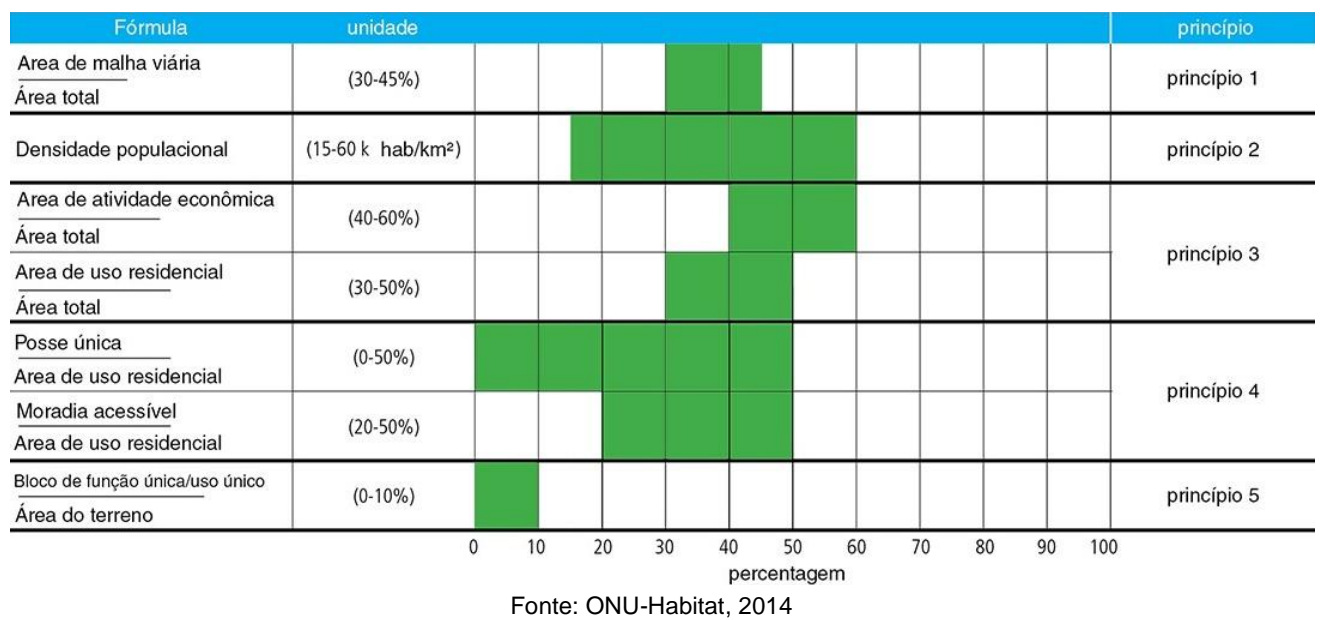

As preocupações globais sobre o desenvolvimento sustentável, no que diz respeito às vizinhanças, foram refletidas em uma ampla gama de trabalhos acadêmicos. Bijoux (2012) afirmou, claramente, que um modo de vida sustentável deve acontecer sem esforço, demonstrando que os projetos devem considerar os conceitos de vizinhança sustentável como primícias, uma vez que são benéficos para a comunidade e para o indivíduo, bem como para o meio ambiente. Ercan e Ozden (2014) reconheceram que a vizinhança era a escala mínima para considerar a sustentabilidade social e que a avaliação da sustentabilidade dos bairros precisa considerar as maneiras pelas quais os níveis econômico, ambiental e social se relacionam com as pessoas.

Do ponto de vista da ONU-Habitat, as cidades do futuro devem construir um tipo diferente de estrutura e espaço urbanos, onde a vida prospera e os problemas mais comuns da atual urbanização são contemplados. Entende-se, assim, que a abordagem tratada pela ONU-Habitat (2014) congrega os anseios de pesquisadores, abarcando os três principais recursos de bairros e cidades sustentáveis: compacto, integrado e conectado. Tal abordagem, ainda, permite que seja possível estabelecer mecanismos de avaliação dessas vizinhanças, do ponto de vista da sustentabilidade, a partir dos cinco princípios por ela estabelecidos.

\section{Dubai, Crescimento e Desenvolvimento}

Dentre os poucos estudos sobre a região de Dubai, destaca-se o de Fazal (2005) que, em sua análise da estrutura urbana local, dividiu o desenvolvimento da cidade em quatro períodos diferentes: 1900-1955, 1956-1970, 1971-1980 e 1980-2005. A autora destaca que a economia e a população em crescimento lento caracterizam o primeiro período, quando os habitantes viviam em casas feitas de folhas de palmeira e que, devido à falta de recursos financeiros, a expansão da cidade era limitada, isto é, não havia expansão de terras. Em 1955, a Cidade de Dubai cobria apenas uma área de 3,2 km².

Durante o segundo período, a municipalidade de Dubai foi estabelecida (1957) e os membros do Comitê Governamental foram escolhidos entre os homens de negócios proeminentes. A partir de então, foi elaborado um plano para a criação de um sistema rodoviário e um novo centro administrativo para a cidade. Portanto, com a municipalização, foi iniciado um processo do planejamento para Dubai. No período, também houve modificações na construção civil: a construção de casas feitas de blocos de concreto substituiu as construções de folhas de palmeira. No entanto, a expansão urbana continuou em ritmo lento, mostrando que seria necessária uma organização formal para apoiar o crescimento do local. 
O período de 1971 a 1980 marcou uma forte expansão da área urbana, já que o Emirado possuía mais capital financeiro à sua disposição, em grande parte devido às receitas do petróleo. Após a descoberta do petróleo, em 1966, portanto, é que surgiram os grandes projetos de infraestrutura. Investimentos foram feitos na melhoria do sistema rodoviário, na construção de túneis, pontes, terminais de contêineres, portos comerciais, bem como áreas industriais e residenciais. Percebese, então, que a cidade passa por um processo mais efetivo de desenvolvimento econômico, onde, centros financeiros, comerciais e administrativos foram estabelecidos em diferentes partes da cidade (UMAKOSHI, 2014). Apesar de haver um processo de crescimento acelerado da urbanização, em várias partes do mundo, nas décadas de 1970 e 1980, Elessawy, (2017) destaca que, no período, nenhuma outra cidade do mundo cresceu tão rapidamente quanto Dubai. Entre 2004 e 2006, os projetos imobiliários prosperaram e a falta de espaço para a construção levou a cidade a se expandir nas direções que o território possibilitava: o deserto e o mar. Esses aterros são representados, em sua maioria, pela criação das ilhas artificiais.

Observa-se, assim, como o crescimento econômico de Dubai foi importante para o desenvolvimento local e permitiu que a cidade se caracterizasse pela realização de vários megaprojetos, como o Hotel Burj Al Arab (único hotel sete estrelas do mundo); e as ilhas artificias, como as palmeiras e a The World, (300 ilhas artificiais que representam o mapa mundial), cujas formas são melhor percebidas em vista aérea e que abrigam residências, comércio, e entretenimento (BAGAEEN, 2007).

\subsection{A Composição da Sociedade em Dubai e Seus Valores Culturais}

No início dos anos 1960, antes do estabelecimento da economia do petróleo, duas orientações principais moldaram a cultura tradicional do Emirado: uma orientada para o deserto, representada pelos beduínos, nômades cuja agricultura de subsistência funcionava como uma oásis no deserto, que não gerava altos recursos financeiros para o país, e a cultura orientada para o mar, que girava em torno do comércio marítimo e de pérolas (KHALAF, 2001). Essas subculturas eram econômica, política e socialmente interdependentes, criando uma cultura comum e uma identidade social, e os Emirados Árabes Unidos compartilhavam aspectos significativos de sua etnicidade com os países árabes vizinhos e com a vivência árabe mais ampla.

Antes de 1970, a população local ainda era pequena (estimada em 86 mil, em 1961). A produção comercial de petróleo provocou um rápido crescimento populacional. Como resultado desse processo, houve um aumento na população nacional e melhorias na alimentação, nos cuidados de saúde e nos padrões de vida da população. Em contrapartida, a imigração de trabalhadores estrangeiros cresceu em larga escala, na sua maioria do sexo masculino, para suprir as necessidades de mão-de-obra locais (MANSOUR; ELSHAHIN, 2014). Este último fator gerou uma dependência do trabalho expatriado; os EAU tornaram-se uma sociedade multiétnica e os cidadãos dos Emirados respondem por apenas $20 \%$ da população, pois cerca de dois terços dos imigrantes são asiáticos, principalmente da Índia, Paquistão, Irã, Sri Lanka, Bangladesh e Filipinas. O restante da população, hoje, é formado por árabes, europeus e americanos (KHALAF, 2001). A maioria da população original dos Emirados Árabes Unidos é de alta renda. Os imigrantes europeus e americanos, de modo geral, também possuem alto poder aquisitivo, mas os trabalhadores, comumente oriundos de regiões mais pobres, funcionam como mão-de-obra barata e não possuem renda; são estes os mais encontrados na região (DE BEL-AIR, 2015).

Dubai tornou-se uma área de fronteira onde ocorre uma variedade de conflitos culturais: Ocidente- 
Oriente, modernismo-fundamentalismo árabe e asiático, que geram conflitos tratados pela política do Estado, que garante direitos apenas aos cidadãos dos Emirados Árabes Unidos. A Constituição dos EAU afirma, em seu Artigo 25: "Nenhuma discriminação deve ser praticada entre cidadãos da União em razão de raça, nacionalidade, crença religiosa ou posição social." (EAU, 1971), mas não se percebe uma política clara para garantir direitos aos imigrantes. Os Emirados Árabes Unidos não adotam uma lei para naturalizar profissionais estrangeiros que contribuem significativamente para a economia e o bem-estar nacionais. Os líderes acreditam que os cidadãos naturalizados não podem ser totalmente confiáveis, especialmente em situações de crise, uma posição que pode estar enraizada na sociedade tribal, onde a família é a base, enquanto os estrangeiros não fazem parte dela.

Deste modo, no caso de Dubai, as alterações sociais foram significativas, pois resultaram num processo migratório amplo, que atraiu para a região novos moradores e turistas de várias partes do planeta, com hábitos e costumes - enfim, de diferentes culturas. Esta mistura social representa os desafios mais sérios enfrentados por nações em desenvolvimento, como equilibrar os benefícios do desenvolvimento urbano às mudanças que dele provêm (MANSOUR, 2015).

\section{Estudo de Caso da Ilha Palm Jumeirah}

De todas as ilhas artificiais de Dubai, a Palm Jumeirah foi a primeira a ser construída. Seu processo de construção começou em agosto de 2001 e foi concluído em 2013. A partir de pesquisas iniciais, a Van Oord, empresa holandesa especializada em dragagem e recuperação de terras, foi contratada para elaborar relatórios sobre os impactos do projeto (ROB E DE JONG et al., 2003).

O Plano Diretor da ilha, como mostrado na figura 3, foi projetado para acomodar diferentes aglomerados residenciais e grandes áreas de praias recreativas. $O$ tronco de $2 \mathrm{~km}$ de extensão é o centro da ilha onde estão os apartamentos. Também há alguns hotéis, um shopping center e um parque público. As frondes que contém os 17 ramos da palmeira são conectadas por estradas que levam ao tronco e abrangem casas que têm praias privadas, e podem receber 60.000 residentes, oferecendo uma variedade de modelos e estilos. O crescente (quebra-mar) é conectado ao tronco por uma linha de metrô e por um túnel submarino (GHAFFARI, 2017); ele contém cinco resorts de praia, quatro marinas e inclui uma variedade de lojas, cafés, restaurantes, opções de entretenimento, hotéis cinco estrelas, marinas, e praias de luxo na costa.

Figura 3: Zonas da Palm Jumeirah

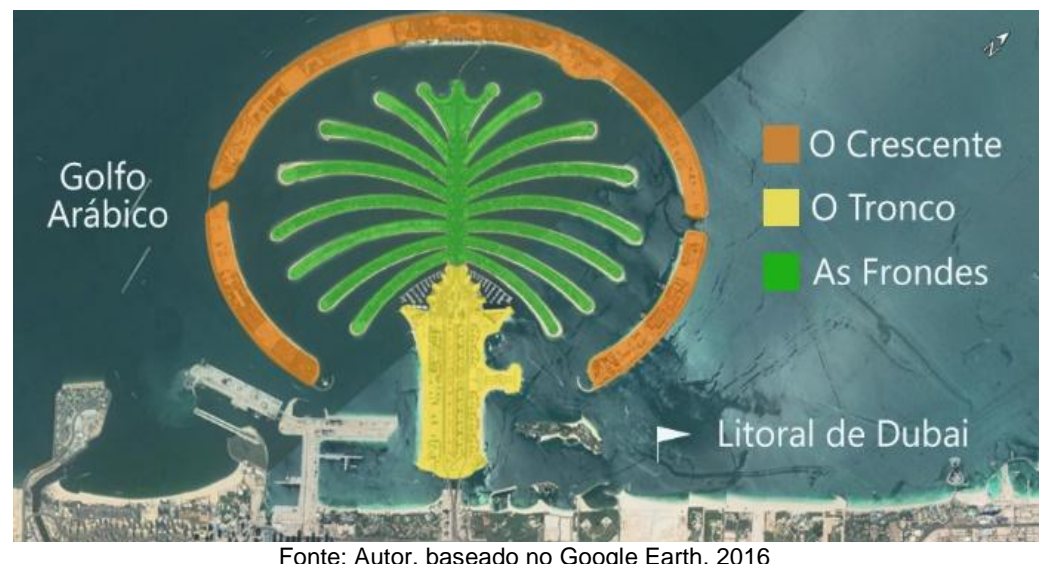

Fonte: Autor, baseado no Google Earth, 2016 
A construção foi iniciada pelo quebra-mar, que abrange $11 \mathrm{~km}$ de comprimento (SIMON HELLEBRAND et al., 2004). A palmeira é constituída principalmente de areia, a mesma que foi utilizada no quebra-mar. Foram remanejadas 94 milhões de metros cúbicos de areia, retirados de diferentes trechos do mar de Dubai, para a fundação da ilha, modificando os ecossistemas marítimos. Após este processo, quando a areia atinge o nível do mar, foi iniciado o processo de rainbowing (descarga de grandes quantidades de areia em locais rasos), que continua a etapa de aterramento, complementando com areia, acima do nível do mar. O desenho preciso dos dezessete ramos da palmeira e do o processo de aterramento foi realizado com auxílio de Sistema de Posicionamento Global (GPS), de acordo com a NASA (2006).

\subsection{Análise dos impactos gerados na llha, de acordo com as três dimensões da sustentabilidade}

\subsubsection{Análise ambiental}

Como uma forma mais didática de apresentação, a análise ambiental foi dividida em três partes e realizada a partir da revisão bibliográfica, considerando que os impactos ambientais causados pelas ilhas artificiais são muito diversos. Para tanto, este estudo priorizou três fases: [A] projeto; [B] construção; e [C] a nova malha urbana da ilha.

Ao começar pelo projeto $[\mathrm{A}]$, verifica-se que, pela forma dos ramos, criam-se espaços que dificultam a circulação da água. A água do quebra-mar não estava circulando conforme o esperado, causando áreas de estagnação ao redor das folhas. O quebra-mar - o crescente - foi redesenhado para fornecer duas aberturas para melhorar a circulação da água. Há evidências de sucesso e melhorias intensas na circulação em catorze dias. A escolha do formato das palmeiras não é das mais adequadas para preservação e sustentabilidade ambiental. De acordo com Van Lavieren (2012):

Apesar de as ilhas obstruírem os fluxos naturais das marés nas costas, a água estava relativamente bem incorporada à ilha, exceto pelo lado oeste do tronco entre as frondes [...] foi constatado fluxo desigual nos lados leste e oeste da ilha. (VAN LAVIEREN et al., 2012, p.20)

Da mesma forma, como seus ramos são longos e não permitem o uso de sistemas de transporte coletivo, as caminhadas a pé ou de bicicleta tornam-se insuportáveis devido ao clima de Dubai, que apresenta altas temperaturas. Este fato força o uso do automóvel, aumentando o calor e a poluição do ar (TINTAWI, 2009).

Quanto à construção [B], Salahuddin (2006), afirmou que a palmeira afeta diretamente uma área de 25 quilômetros quadrados, com um comprimento de $5 \mathrm{~km}$ e largura de $5 \mathrm{~km}$. As manchas de sedimentos suspensos se estendem por mais de $25 \mathrm{~km}$ para a esquerda e $25 \mathrm{~km}$ para a direita da Palm Jumeirah. Portanto, a construção dessa ilha afeta efetivamente pelo menos 75 quilômetros quadrados do ambiente marinho. Além disso, as praias próximas às Palm Islands sofreram muito com a perda de areia, especialmente as praias ao leste das ilhas, que é a direção principal da transferência de sedimentos. Na construção, a Nakheel deveria usar telas de lodo para evitar que os sedimentos finos se espalhassem pelas áreas próximas às Palms. No entanto, segundo o Dr. 
Tom Williams ${ }^{2}$, essa técnica não foi utilizada (FAKHRO, 2013). O aumento da turbidez causada por níveis mais altos de material em suspensão afetou a luz disponível para atividades fotossintéticas essenciais às comunidades bentônicas ${ }^{3}$. Altos níveis de material em suspensão causaram perda de fauna bentônica por entupimento dos mecanismos de alimentação e sufocamento (AL-JAMALI et al., 2005).

Em Palm Jumeirah, em 8 de janeiro de 2005, três recifes de corais e um recife de Svenner

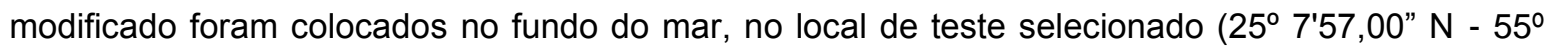
6'59,7"). Hopkins (2007) afirma que, em seis meses de sua implantação preliminar, os recifes haviam demonstrado capacidade de formar um habitat extraordinariamente bom para a colonização de uma ampla gama de espécies de organismos bentônicos sésseis, incluindo corais e moluscos.

A modificação das ondas resultou em mudanças drásticas no transporte costeiro, bem como no potencial de evolução da linha costeira ao longo do segmento III (MANGOR ET AL., 2008). Segundo estimativas do ex-consultor técnico sênior da Nakheel, as três Palms corroeram mais de 40 quilômetros de costa natural dos 65 quilômetros de Dubai (SALAHUDDIN, 2006). Mangor et al. descobriram que, para fornecer soluções estáveis e sustentáveis a longo prazo, recomenda-se a nutrição:

As medidas propostas têm natureza temporária. Geralmente, a nutrição é recomendada até que esquemas mais permanentes possam ser projetados e implementados. O registro de riscos para a situação de longo prazo identifica áreas que estão levando à perda de recursos da praia ou a danos nas instalações e ativos costeiros (habitação, infraestrutura, etc.). (MANGOR et al., 2008, p.13)

Dubai está perto de uma zona de terremoto e, caso o fenômeno aconteça, a areia poderá passar por um processo conhecido como liquefação e causar o afundamento da ilha. Antes da construção da malha urbana, testes geofísicos mostraram que a areia usada não suportava a enorme quantidade de edifícios e infraestrutura planejada e que ela precisaria ser compactada para fornecer uma base estável para a construção. Segundo Patnik (2015), ela foi submetida a um processo de compactação vibracional, reduzindo a possibilidade de assentamentos futuros.

A intrusão da água do mar e seu movimento no solo podem causar danos à vegetação e ao próprio solo pelo excesso de sal. Assim, a camada de geotêxtil foi instalada para impedir que as raízes puxem água através do solo, causando a intrusão de água do mar para estabilizar a sub-base de, por exemplo, estradas e impedir a mistura de materiais, permitindo o livre movimento da água. $\mathrm{O}$ Fibertex F-2B foi utilizado na construção da infraestrutura (PATNAIK, 2019).

Outra questão enfrentada pela ilha e ainda sem solução é o aumento do nível do mar. O Painel Intergovernamental sobre Mudanças Climáticas (Intergovernmental Panel on Climate Change IPCC) declara, especificamente em relação às ilhas, que o "alto índice de área costeira e massa terrestre fará da adaptação um desafio financeiro e de recursos significativo" (IPCC, 2014, p. 24). Cerca de $85 \%$ dos residentes dos Emirados Árabes Unidos vivem em áreas costeiras, e as ilhas artificiais também estariam em risco por causa das mudanças climáticas e do aumento do nível do

\footnotetext{
${ }^{2}$ O Dr. C. Thomas Williams (Doutorado (Geologia / Zoologia), Universidade da Califórnia, Berkeley, 1976) é ex-consultor técnico sênior da Nakheel.

${ }^{3}$ Comunidades bentônicas são o conjunto de organismos que vivem alocados no fundo do mar, para fixá-lo, escavar nichos, mover-se em sua superfície ou nadar nas proximidades sem sair dele.
} 
mar (MALEK, 2017). Como o risco é um múltiplo de vulnerabilidade e gravidade do perigo (PORTMAN, 2019), a construção da Palm Jumeirah parece estar separada da realidade da mudança climática e, portanto, configura um empreendimento altamente arriscado.

No que diz respeito à construção de nova malha urbana [C], a realização de instalações recreativas, restaurantes e acomodações utilizou, extensivamente, recursos e energia e resultou em aumento da poluição do ar e da água. Para resolver problemas pendentes, a Nakheel também monitorou os proprietários das empresas que compraram as propriedades quanto ao desempenho ambiental: "A empresa afirmou que os empreendedores são obrigados a fazer esforços razoáveis para cumprir as diretrizes de gestão ambiental [...] se não, eles terão pontos negativos de desempenho (PNIs)" (SALAHUDDIN, 2006, p.76). Os empreendedores obtêm esses pontos quando não conseguem atingir determinado desempenho ambiental, permitindo a erosão do solo, aumentando a poluição (inclusive sonora), descarregando no mar, causando perda de habitat natural, aumentando a pressão sobre espécies ameaçadas, entre outros. Empreiteiros com um número significativo de centrais nucleares serão preteridos em investimentos futuros em licitações.

\subsubsection{Análise social}

As principais questões relacionadas aos aspectos sociais que a ilha apresenta são voltadas à implantação das áreas residenciais, que não apresentam espaços de uso público - as praias são privadas e não permitem a interação da população (TINTAWI, 2009). Os trabalhadores imigrantes são proibidos de entrar em contato com as residências e os acessos à llha são separados, aumentando a exclusão social, que se verifica entre essas pessoas.

Um aspecto positivo da construção das ilhas foi o surgimento de benefícios econômicos que também se refletem no social, pela criação de empregos que levou a um influxo de trabalhadores em todos os níveis e de várias nacionalidades. Houve, também, um aumento do número de trabalhadoras que vêm de Filipinas e da Indonésia para atuar como empregadas domésticas (SABBAN, 2019). Por outro lado, este fato causou a redução do percentual de trabalhadores nativos e árabes, gerando um forte desequilíbrio demográfico. Para solucionar este problema foi estabelecido um comitê, em nível ministerial, para encontrar formas retomar o balanceamento. Em seguida, foram criadas regulamentações proibindo os trabalhadores com baixos salários de trazerem suas famílias com eles. Com isso, o Estado acabou criando problemas em relação aos aspectos humanitários e assuntos externos (GHAEMI, 2006).

Observa-se que a relação que se estabelece entre Governo e trabalhadores imigrantes tem mão única, pois, enquanto estes participam ativamente do crescimento da construção civil (e, indiretamente, da ampliação do setor imobiliário), fortalecendo a economia do país, não usufruem de direitos trabalhistas (e humanitários) mínimos para sua subsistência. Salários condizentes com a jornada de trabalho (alguns trabalham mais de dez horas diárias), alimentação (eles precisam arcar com os custos) e outros benefícios em geral, não são dados à classe trabalhadora. Trabalhadores da construção civil imigrantes estão alojados em campos de trabalho sancionados pelo Estado, ocultos da vista do público (ANDERSON, 2009).

Esta parcela da população viaja de ônibus de seus campos de trabalho no Deserto, onde vivem em quartos com até vinte homens. Deste modo, aos trabalhadores imigrantes não são garantidas condições de estadia e trabalho mínimas para oferecer-lhes qualidade de vida e respeito humano. A maioria dos trabalhadores imigrantes é muito pobre e questiona a problemática exposta, como 
falta de moradias adequadas. Eles convivem em situação precária, sem infraestrutura básica e sem segurança. No quadro 1, apresentam-se quatro espaços que integram a moradia desses trabalhadores: espaços coletivos, muitas vezes mal ventilados, sem revestimento e amontoados, onde os quartos são divididos por até vinte pessoas, sem divisórias, e não existem espaços livres comunitários para o descanso, nem mesmo separação entre os usos.

Quadro 1: A situação das instalações do acampamento em Al Rashidiya

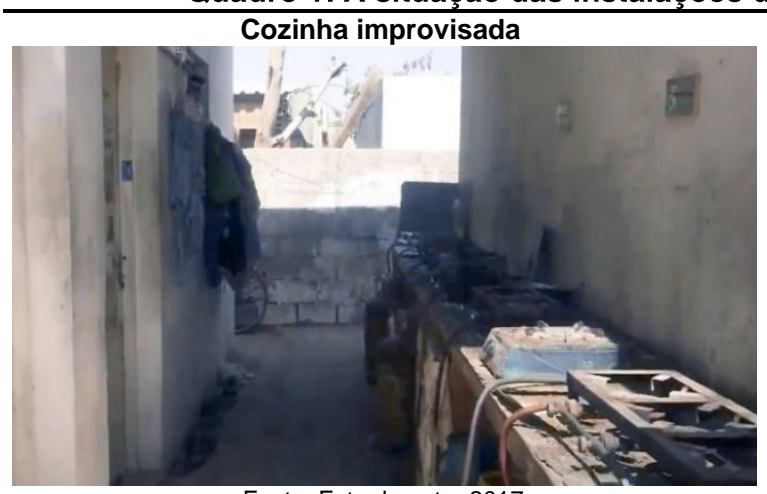

Fonte: Foto do autor,2017

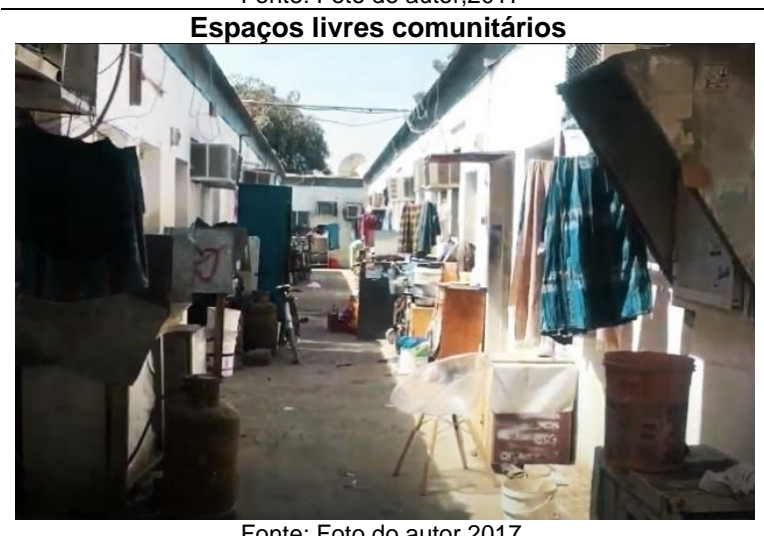

Fonte: Foto do autor,2017

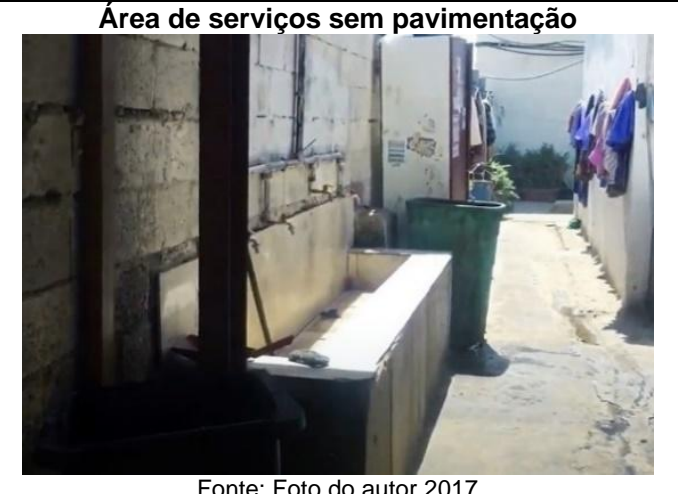

Fonte: Foto do autor,2017

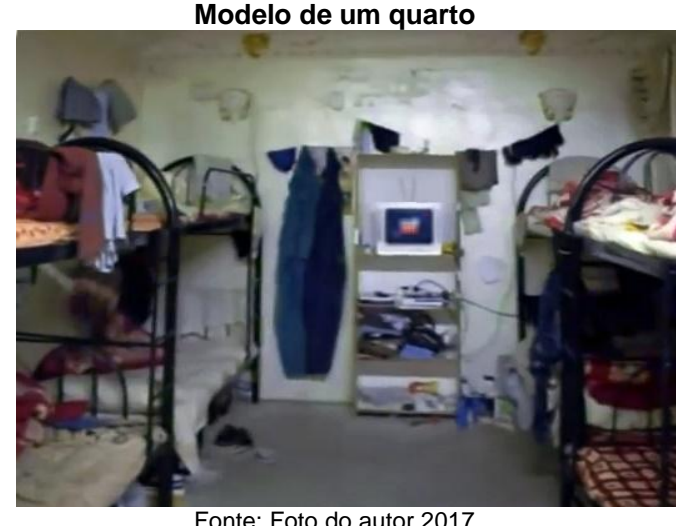

Fonte: Foto do autor,2017

Portanto, os migrantes estrangeiros passaram anos trabalhando no Palm Jumeirah sem subsídios do Governo e sem direitos trabalhistas, tendo, inclusive, seus passaportes retidos pelos contratantes por causa do sistema Kafala ${ }^{4}$ sem possibilidade de retornar a seus países (ESSAID, 2010). Este talvez seja o mais crítico problema social gerado em Jumeirah: a falta de ações que ofereçam maior dignidade aos imigrantes, pois o Estado lhes impõe condições de vida subhumanas não reconhecendo a importância da vida (questão social) nem mesmo a importância econômica, uma vez que são estes trabalhadores que permitem o crescimento da economia da região, pelo crescimento das construções e, sobretudo do setor imobiliário (SÖNMEZ et al., 2011).

Do ponto de vista do Governo, a principal motivação para a construção de Palm Jumeirah foi ampliar as atividades econômicas de turismo. Nos últimos anos, festas noturnas com bebidas

\footnotetext{
${ }^{4}$ O Sistema define que os trabalhadores tenham um patrocinador no país, geralmente seu empregador, que é responsável por seu visto e status legal. Essa prática tem sido criticada por organizações de direitos humanos por criar oportunidades fáceis para a exploração de trabalhadores. De acordo com Degorge (2006), o sistema Kafala tem sido descrito como a escravidão moderna, deixa os trabalhadores migrantes vulneráveis ao tráfico de seres humanos e às práticas de trabalho forçado e resultou em graves violações dos direitos humanos.
} 
alcoólicas tornaram-se muito comuns, e a Palm Jumeirah tem muitos tipos de boates e bares para atender aos turistas (AL DARMAKI, 2008), o que também não é apreciado na cultura árabe.

O estilo de vida ocidental tem influência na cultura de Dubai, mudando o comportamento da população, especialmente os jovens. Podem-se observar dois grupos sociais diferentes existentes, atualmente, no local: os conservadores, que se recusam a adotar o comportamento e as ideias ocidentais, isolando-se e às suas famílias das atividades sociais; e os jovens que mais facilmente aceitam e se adequam a uma cultura diferente, em vez de se adaptarem à cultura local (DIAS, 2014).

É notório que as mudanças de comportamento preocupam os conservadores, que percebem nesta intromissão uma ameaça à sua própria identidade social e religiosa (KHAMIS, 2017). Assim, os jovens observam que muitos dos costumes e tradições começaram a mudar, como por exemplo, a troca do idioma comumente falado (do árabe para o inglês), pela absorção do uso de novo estilo de vestimentas e, sobretudo pelo costume tradicional de homens e mulheres não se relacionarem em público (KHAMIS, 2017).

\subsubsection{Análise econômica}

Ao analisar a situação econômica, fica claro que, desde a construção das Palms Islands, o produto interno bruto (PIB) de Dubai cresceu consideravelmente. O maior crescimento nominal foi registrado em 2005 (cerca de 27\%) e representou uma parcela considerável do PIB total dos EAU (29\% em 2005). O setor petrolífero representava uma participação decrescente na economia de Dubai. O Governo criou sistemas para que os estrangeiros pudessem trazer mais investimentos para o local. Portanto, do ponto de vista da economia, Dubai parece investir visando, sempre ao crescimento. No entanto, observa-se que estes recursos são sempre aplicados aos setores mais abastados e que os imigrantes continuam sobrevivendo em condições de miséria.

A construção da Palm Jumeirah Island, em 2001, foi o projeto de maior prestígio, atraindo empresas estrangeiras e desenvolvendo o setor turístico. A indústria do turismo estabeleceu muitas oportunidades de emprego em vários campos (alimentação, compras, transporte, entre outros). No entanto, existem problemas, como o desequilíbrio entre a força de trabalho estrangeira e a força de trabalho local. É a mão de obra estrangeira que domina o mercado de trabalho, sobretudo o da construção. A figura 4 mostra o percentual de imigrantes que chegaram a Dubai entre 2002 e 2013. Nela é possível observar que a maior parte dos imigrantes é oriundo da Índia (acima de 40\%) e que ainda vinha crescendo em relação a 2002 sobretudo em relação à população nativa. 
Figura 4: Comparação do percentual de empregados por nacionalidade entre 2002 e 2013 indexada na base de dados de Departamento de Estatística, Dubai

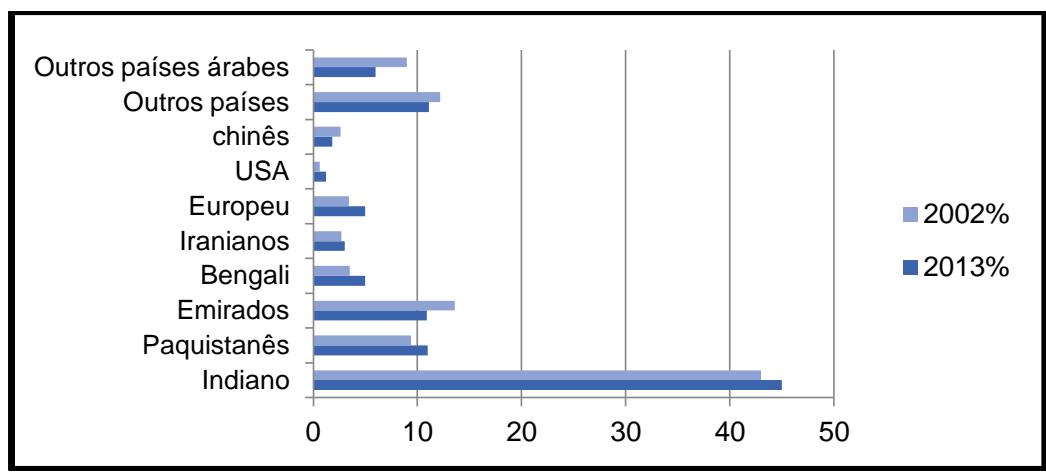

Fonte: Dados obtidos de Centro Estático de Dubai (2002 e 2013)

A economia da região é basicamente oriunda do turismo, uma vez que este grande contingente de trabalhadores imigrantes, cujos salários são reduzidos, precisam enviar parte dele a seus familiares em seus países de origem uma vez que não lhes é permitido trazê-los para Dubai.

As empresas transnacionais realizaram projetos significativos na Palm Jumeirah, que exigiram enormes quantias de financiamento. As vantagens dos projetos foram a localização privilegiada e forma única da ilha, permitindo-lhe atrair investimentos competitivos. $O$ anúncio da construção de mais duas ilhas-palmeiras ( $P a l m$ Jebel Ali e Palm Deira) diminuiu o fluxo de investimentos na ilha de Palm Jumeirah.

Terrenos e apartamentos nos projetos na ilha Palm Jumeirah foram vendidos e revendidos muitas vezes, mesmo antes do início da construção. Os projetos imobiliários tiveram benefícios rápidos e de curto prazo, com a ajuda de banqueiros e hoteleiros internacionais que se beneficiam do turismo. O gerente de marketing da Al Khayat Real Estate notou que

Há tanta demanda dos compradores; é difícil atender à exigência com uma ilha. Atualmente, o Palm Office tem uma lista de espera de mais de 800 pedidos. Com quase $90 \%$ das unidades colocadas à venda já vendidas, acreditava-se que as 1100 unidades nas nove frondes seriam vendidas em 10 dias. (EHSAN, 2005, p.4)

Cerca de 70\% dos compradores são cidadãos dos Emirados Árabes Unidos, mas, muitos deles, já tinham vendido seus terrenos quando os preços subiram em 2005 (Tabela 1).

Tabela 1: A propriedade dos imóveis na ilha de Palm Jumeirah por país, Emirados Árabes Unidos, Dubai

\begin{tabular}{lc}
\hline Nacionalidades dos Compradores & $\%$ \\
\hline Emirados Árabes Unidos (EÁU) & 12 \\
Conselho de cooperação do golfo (GCC) & 24 \\
Europa & 21 \\
Estados Unidos da América (EUA) & 5 \\
Outros países Árabes & 8 \\
Índia & 14 \\
Paquistão & 4 \\
Rússia, & 7 \\
Países Africanos & 1 \\
Outros países & 4 \\
\hline Total & $\mathbf{1 0 0}$ \\
\hline Fonte: Dados obtidos de Departamento de Organização Internacional para a Migração, 2005
\end{tabular}


Por conseguinte, o projeto da ilha Palm Jumeirah foi realizado com investimento estrangeiro. A Tabela 2 mostra que os custos totais da Palm Jumeirah foram de US $\$ 6,5$ bilhões. A participação do Governo foi de US \$600 milhões, a do setor privado local de US $\$ 420$ milhões, e dos Estados do Golfo de US \$1,9 bilhão, enquanto o restante foi composto de investimento estrangeiro direto somando US \$ 3.580 milhões, que constituíram cerca de $85 \%$ do investimento total do projeto.

Tabela 2: Total de Investimentos de empresas globais, regionais e locais na ilha de Palm Jumeirah, Emirados Árabes Unidos, Dubai, abril de 2005

\begin{tabular}{lllll}
\hline Pais & $\begin{array}{l}\text { Número de } \\
\text { empresas }\end{array}$ & $\%$ & $\begin{array}{l}\text { Valor do investimento (Milhões } \\
\text { de dólares) }\end{array}$ & $\%$ \\
\hline Conselho de cooperação do golfo (GCC). & 7 & 13,7 & 1800 & 27,7 \\
Emirados Árabes Unidos (EÁU). & 11 & 21,6 & 420 & 6,5 \\
Governo local. & 1 & 2 & 600 & 9,2 \\
Outros países. & 6 & 11,8 & 320 & 4,9 \\
Cingapura. & 5 & 9,8 & 160 & 2,5 \\
Estados Unidos da América (EUA). & 8 & 15,7 & 2550 & 39,2 \\
Reino Unido. & 4 & 7,8 & 200 & 3,1 \\
Alemanha. & 3 & 5,9 & 70 & 1,1 \\
Holanda. & 2 & 3,9 & 150 & 2,3 \\
Japão. & 4 & 7,8 & 230 & 3,5 \\
\hline
\end{tabular}

Fonte: Dados obtidos de Departamento de Desenvolvimento Econômico de Dubai (2005)

Os fluxos de Investimento Estrangeiro Direto (IED) afetaram os preços dos imóveis em Dubai e outros emirados. A inflação é um problema, além de transformações espaciais, econômicas, políticas, sociais, culturais e ambientais. Os Emirados Árabes Unidos conseguiram atrair mais de dois terços (70\%) dos "megaprojetos" imobiliários na Região do Golfo, sendo que Dubai concentra $51 \%$ deles (EHSAN, 2005).

O dinâmico mercado imobiliário dos Emirados Árabes Unidos, nos últimos cinco anos, atraiu mais de US $\$ 300$ bilhões em compromissos de investimentos locais, regionais e internacionais no País, resultando que Emirados Árabes Unidos obteve a melhor classificação de investimento de todos os países do Conselho de Cooperação do Golfo (CCG) em investimentos imobiliários.

\subsection{Os cinco princípios de sustentabilidade da ONU-Habitat aplicados à ilha Palm Jumeirah}

Iniciou-se a análise pela divisão da área de estudo em seis zonas para facilitar a coleta de dados, quais sejam: área residencial unifamiliar; residencial multifamiliar; hoteleira; comércio em geral; uso misto e espaços públicos (quadro 3). A demarcação da zona foi realizada sobre a imagem de satélite (Google Earth), documentos oficiais e nas visitas iniciais de campo. O estudo de campo anotou as características do solo urbano (por exemplo, edifícios e estradas) de acordo com sua localização e dados como a função da unidade e a área total para cada uso. O quadro 2 mostra a localização da área de estudo com a imagem de satélite da ferramenta Google Earth. 
Quadro 2: Estudo da área

\begin{tabular}{ll|l|}
\hline & Residenciais \\
(Casas)
\end{tabular}

Os princípios de sustentabilidade definidos pela ONU-Habitat mostram que, na ilha Palm Jumeirah, o princípio 1 (criação de espaços adequados para ruas e para uma malha urbana eficiente) não é atendido. De acordo com os levantamentos de campo que auxiliaram o mapeamento de uso do solo urbano, observou-se que são ocupados apenas $15 \%$ do solo para este fim e, ainda não dispõe de espaços públicos suficientes para o lazer da população (quadro 2). O sistema viário não prevê rotas para pedestres ou ciclistas na vizinhança (quadro 3, figura A). Não há áreas livres destinadas ao uso público na ilha. O único espaço "livre" está localizado sob a linha do metrô, e é denominado parque público ( $\mathrm{Al}$ Ittihad). No entanto, os moradores não o utilizam e os motivos para este esvaziamento espacial, provavelmente, se dão em função da sua localização, ausência de mobiliário e, ainda, devido ao estilo de vida dos moradores, que se isolam das classes sociais mais baixas (quadro 3, figura $B$ ). 
Quadro 3: Observações das visitas ao local relacionado a malha urbana

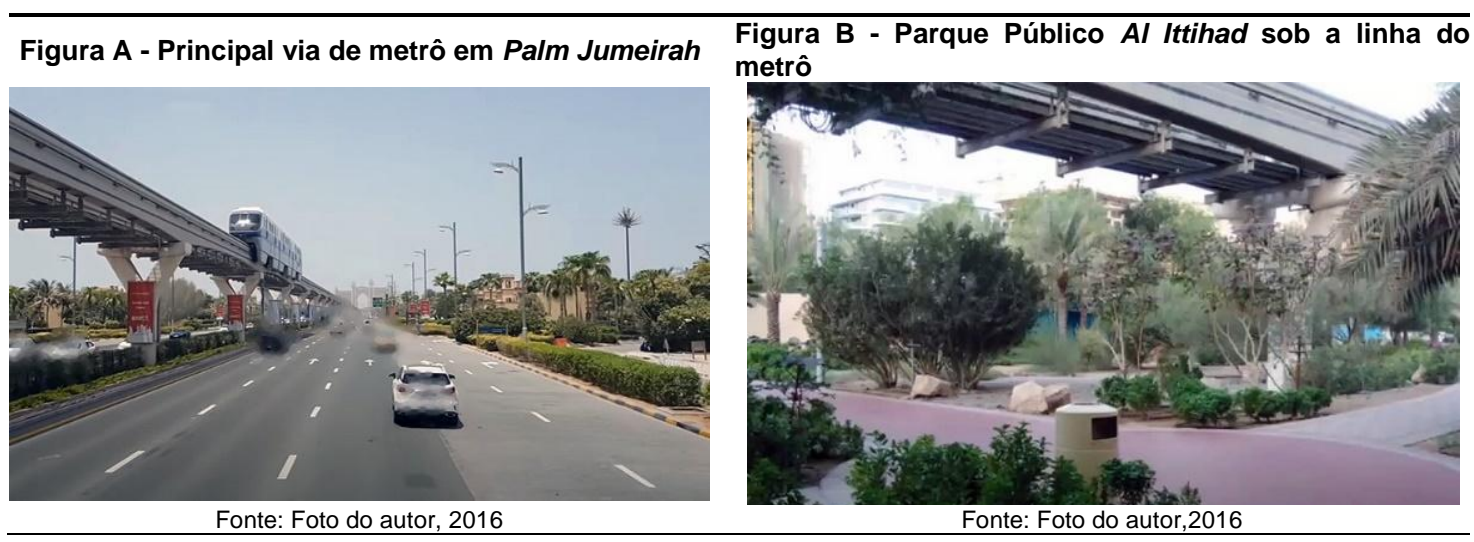

No princípio 2, a área atende às determinações, pois apresenta uma densidade maior que 15.000 habitantes $/ \mathrm{km}^{2}$, abrigando uma população de $22.333 \mathrm{hab} . / \mathrm{km}^{2}$, segundo documentos oficiais divulgados pelo Governo de Dubai, através do Centro de Estatísticas de Dubai (2018).

O princípio 3 é contemplado na ilha, uma vez que $42 \%$ da área total de construção é dedicada a atividades econômicas, reunindo a criação de escritórios, shoppings centers, resorts e hotéis, dados obtidos nos levantamentos de campo. Os serviços de todo o distrito possuem: uma mesquita e áreas de lazer que incluem cafés, restaurantes, hotéis, e um shopping (quadro 4). Por outro lado, faltam muitos serviços essenciais, incluindo clínicas, escolas e serviços públicos.

Quadro 4: Atividades econômicas

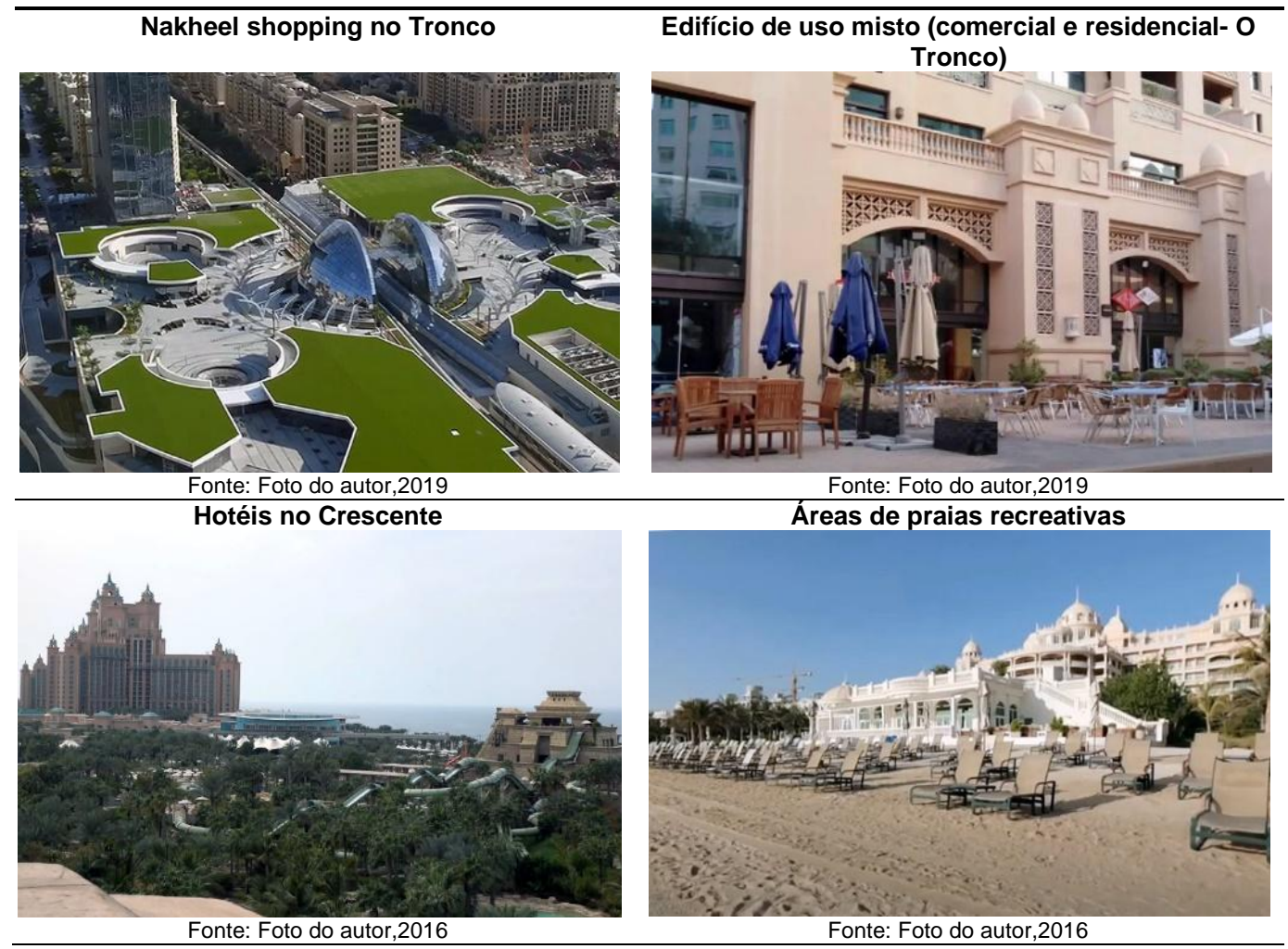


O princípio 4 não é atendido, pois a ilha consiste em um único tipo de posse, qual seja: freehold tenure $^{5}$ - dado também foi obtido a partir de dados oficiais do Governo (LOOK UP, 2015). A ilha não promove uma miscigenação social, funcionando como um condomínio de alto padrão econômico, restrito ao restante da comunidade. Não há habitações destinadas à população mais carente, pois o objetivo da Palm é atrair investidores e turistas ricos para aumentar a economia do país, apresentando prédios e vilas de luxo (AMROUSI et al., 2019).

Finalmente, enfocando o quesito 5 , que foi verificado nas visitas de campo, também não se atinge o princípio estabelecido pela ONU, pois não há promoção da especialização limitada no uso da terra, para restringir o uso único de quarteirões ou vizinhanças, onde blocos com um único uso não devem exceder $10 \%$. Observa-se que as edificações dos ramos abrigam, apenas, o uso residencial, unifamiliar, perfazendo $36 \%$, sem apoio de comércio e serviços. O desenho comporta duas linhas de casas separadas por uma via veicular, sem espaços para pedestres ou ciclistas (quadro 5).

\section{Quadro 5: Observações das visitas ao local relacionado a blocos com uso único}

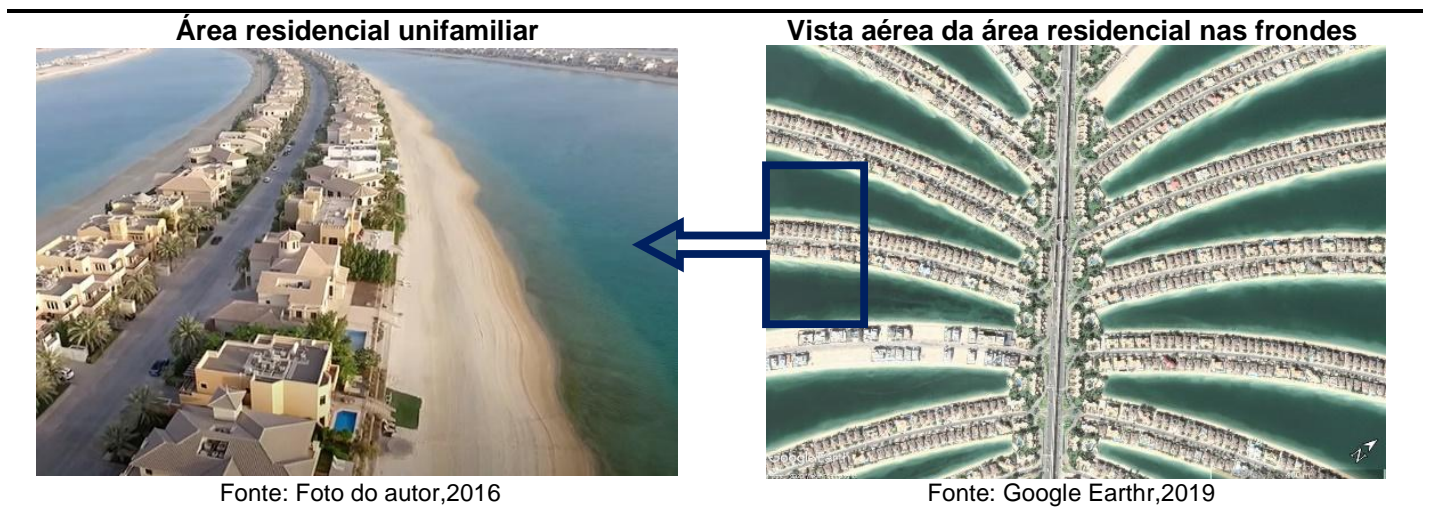

A figura 5 apresenta, de forma resumida, os percentuais dos dados apreciados segundo os cinco princípios da sustentabilidade (ONI-Habitat) na Ilha Palm Jumeirah.

\footnotetext{
${ }^{5}$ A posse classificada como freehold tenure é aquela em que o dono tem posse absoluta da propriedade, inclusive do terreno da construção.
} 
Figura 5: Aplicação dos cinco princípios da ONU-Habitat à ilha Palm Jumeirah

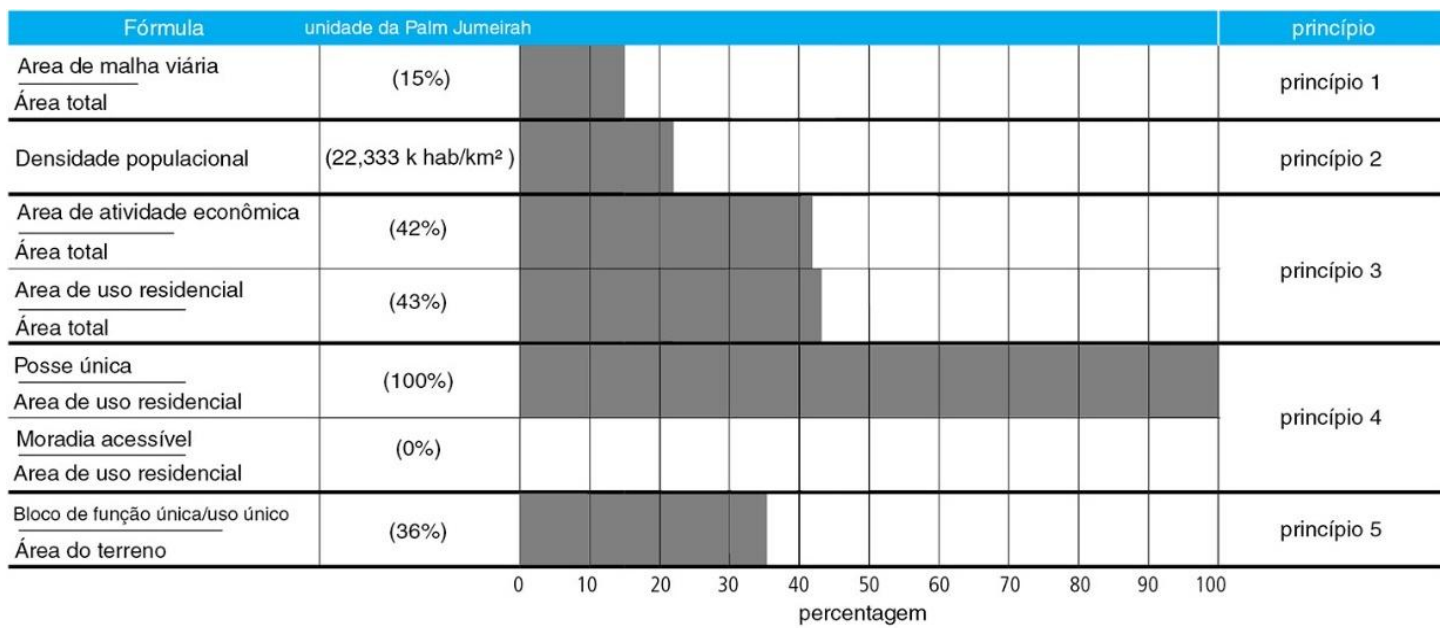

Fonte: Autora, 2019

\section{Conclusão}

Este artigo argumentou que a adoção da política de ilhas artificias como vizinhanças teve consequências econômicas positivas, mas teve, também, um alto custo ambiental e impactos sociais positivos e negativos para Dubai. Até a década de 1990, acreditava-se que a população local era socialmente conectada e tinha hábitos domésticos e crenças sociais comuns (KHALAF, 2001). Os conflitos entre as gerações resultaram na ausência de um estilo de vida local e de uma continuidade social, o que tornou a Palm Island um lugar desconectado de suas ligações culturais com a vida dos Emirados. Houve uma imigração, em grande escala, que mudou a cultura local. Uma nova direção social e cultural surgiu.

A ilha Palm Jumeirah tem um alto custo ambiental. O design da ilha gerou um sistema de transporte rígido, aumentando a dependência do automóvel para o deslocamento da população e restringindo ainda mais o acesso à área. Da mesma forma, criou espaços que dificultam a circulação da água do mar e, com isso, alterando o ecossistema marinho e gerando mau cheiro no ambiente. A construção da llha, a aumenta a propagação de sedimentos em suspensão afeta diretamente o meio marinho e a passagem de luz pela água; e a construção das Palm Islands causou erosão nas margens costeiras e tornou a área vulnerável às mudanças climáticas e ao aumento do nível do mar.

A gestão ambiental eficiente nas ilhas pode diminuir os impactos ambientais. Novas soluções precisam ser consideradas, como a aplicação de recifes artificiais que podem recriar uma colônia de sucesso para organismos bentônicos ao redor da área danificada e o uso de telas pode minimizar os impactos ambientais negativos à turbidez no canteiro desde a obra. Ainda para minimizar os problemas decorrentes do processo construtivo das ilhas, pode-se lançar mão do processo de vibrocompactação no início da obra para resolver os problemas de estabilização da fundação da ilha, assim como a aplicação de camadas de geotêxtil, para a proteção quanto à entrada de água do mar durante serviços de pavimentação e paisagismo.

Os problemas ambientais e sociais resultantes da construção da ilha Palm Jumeirah devem servir de exemplo para planejadores de outras regiões. Desta forma, estudá-la com base nos princípios 
estabelecidos pela ONU-Habitat, além de destacar as metas alcançadas e não alcançadas pela ilha, pode contribuir para o projeto de novos espaços, novas vizinhanças sustentáveis.

\section{Referências Bibliográficas}

AL DARMAKI, I. Globalization and urban development: Case study of Dubai's Jumeirah Palm island mega project. 292 f. Dissertação (Doutorado em filosofia). Faculdade de Ciência de engenharia e matemática, Universidade de Southampton, Southampton, 2008.

ALAWADI, K. KHANAL, A. ALMULLA, A. Land, urban form, and politics: A study on Dubai's housing landscape and rental affordability. Cities, v. 81, n. 4, novembro 2018. P.115-130. Disponível em: < http://isiarticles.com/bundles/Article/pre/pdf/95399.pdf>. Acesso em: 17 de maio de 2019.

AL-HAGLA, K. Towards a Sustainable Neighborhood: The Role of Open Spaces. International Journal of Architectural Research, 2(2), 2008, p. 162-177.

AL-JAMALI, F. et al. Contributed Article, A review of the impacts of aquaculture and artificial waterways upon coastal ecosystems in the Gulf (Arabian/Persian) including a case study demonstrating how future management may resolve these impacts. Journal of Aquatic Ecosystem Health \& Management, Vol. 8 No. 1. 2006, p. 81- 94.

ALLEN, Lila. Dark side of the Dubai dream. BBC Panorama. v. 6. 2009. Disponível em: <http://news.bbc.co.uk/2/hi/uk_news/magazine/7985361.stm>.

AL-ULAMA, H. M. J. S. The Federal Boundaries of the United Arab Emirates. 1994. 366 f. Dissertação (Doutorado em Filosofia) - Departamento de Geografia, Universidade de Durham, Durham, 1994.

AMROUSI, M. et al. Building on Water: The Use of Satellite Images to Track Urban Changes and Hydrodynamic Models to Simulate Flow Patterns Around Artificial Islands. In: International Conference on Intelligent Human Systems Integration. Springer, Cham, 2019. p. 363-369.

ANDERSON, B. Slumdogs and Millionaires. Panorama (2009, 4/6). Disponível em: <http://news.bbc.co.uk/panorama/hi/front_page/newsid_7986000/7986756.stm>.

ASSOCIAÇÃO DAS ESTATÍSTICAS DOS EAU. Centro Estático de Dubai. Anuário estatístico do Estado de Dubai. Dubai, 2002. 126p.

$146 p$.

Centro Estático de Dubai. Anuário estatístico do Estado de Dubai. Dubai, 2013.

BAGAEEN, S. Brand Dubai: The Instant City; or the Instantly Recognizable City. International Planning Studies 12(2). Maio/2007. DOI: 10.1080/13563470701486372.

BIJOUX, D. A Neighbourhood Sustainability Framework for New Zealand: Beacon's research and tools. 2012 Beacon Pathway Incorporated. Disponível em:

<http://www.beaconpathway.co.nz/images/uploads/Report_NH2012(3)_A_Neighbourh

ood_Sustainability_Framework_for_New_Zealand.pdf>.

BUILD SAFE, U. A. E. Best practice guidelines for labor camp accommodation welfare: United Arab Emirates, Revision 1 (2009). 2009. Disponível em: 
$<$ http://www.constructionweekonline.com/pictures/PDFs/Interviews/Casamia_Star/bsu_fullguideline s.pdf>.

CENTRO DE ESTATÍSTICAS DE DUBAI. 2018. Disponível em: $<$ https://www.citypopulation.de/en/uae/dubai/admin/>.

DE BEL-AIR, F. Demography, Migration, and the Labour Market in the UAE. Gulf Labour Market and Migration Programme (GLMM). Explanatory Note. No.7. 2015.

DEGORGE, Barbara. Modern day slavery in the United Arab Emirates. European Legacy, v. 11, n. 6, p. 657-666, 2006. Disponível em:

<http://schnellmann.org/essential_files/Wife_Beating_Quran_4_34_CHILDBRIDES_Quran_65_4/IN JUSTICE_AGAINST_MIGRANT_WOMEN_IN_SAUDI_ARABIA.pdf>.

DIAS, G. M. Migração e Crime: desconstrução das políticas de segurança e tráfico de pessoas. 2014. 366 f. Dissertação (Doutorado em Antropologia Social) - Instituto de Filosofia e Ciências Humanas, Universidade Estadual de Campinas, Campinas, 2014.

DUBAI STATITICS CENTER. UEA: Division of Dubai. 2018. Disponível em: <https://www.citypopulation.de/en/uae/dubai/admin/>. Acesso em 4 de março de 2019.

DUXBURY, N. Exploring the role of arts and culture in sustainable urban development, 2001 [online], Table d'H'oteon Building Sustainable Communities: Culture and Social Cohesion. Disponível em: <http://www.cu Itureandcommunities.ca/downloads/Duxbury-urban-sustainability2001.pdf>.

EHSAN, A. Housing boom in the United Arab Emirates. Jornal de Dubai. Dubai, n. 7125, p 2- 5, 6 jan 2005. Entrevista concedida a gerente de marketing da Al Khayat Real Estate.

ELESSAWY, F. The Boom: Population and Urban Growth of Dubai City. Horizons in Humanities and Social Sciences: An International Refereed Journal. 2. 10.19089/hhss. V. 2i2.60. 2017.

EMAD, S. Early Applications of DMT in Dubai in Two Main Projects for Natural and Artificial Earthfill Silty Sand. Artigo apresentado. DMT '15 the 3rd International Conference on the Flat Dilatometer. 14 a 17 de junho de 2015. Roma, Itália.

EMAS, R. The Concept of Sustainable Development: Definition and Defining Principles. Global Sustainable Development Report, Edition Advance Unedited Version. 2015.

EMIRADOS ÁRABES UNIDOS. Constituição dos Emirados Árabes Unidos. Promulgada em 2 de dezembro de 1971. Disponível em:

$<$ https://www.constituteproject.org/constitution/United_Arab_Emirates_2004.pdf>.

Ministério do Migração. Departamento de Organização Internacional para a Migração. Estatísticas da migração e da população migrante do Estado de Dubai. Abu Dhabi, 2005. 143p.

Ministério do Trabalho. Departamento de Desenvolvimento Econômico de Dubai.

Indicadores socioeconômicos: um projeto para o desenvolvimento socioeconômico: Abu Dhabi, 2005. 32p.

ERCAN, M. A., \& OZDEN, M. A. Sustainable Community Assessment in Suburban Residential Neighbourhood. 2014. Disponível em: 
$<$ https://www.academia.edu/7107472/Sustainable_Community_Assessment_in_Suburb an_Residential_Neighbourhood>.

ESSAID, S. Migrant workers under the "kafala" system in the GCC. 2010. Disponível em: $<$ http://www.migrant-rights.org/2010/11/23/migrant-workers-under-the-

\%E2\%80\%9Ckafala\%E2\%80\%9D-system-in-the-gcc/>.

EXPLORING THE WORLD OF PIPING. The Palm Island, Dubai UAE. Disponível em: $<$ http://www.wermac.org/civil_eng/palm_island_dubai.html>.

FAKHRO, E. Land Reclamation in the Arabian Gulf: Security, Environment, and Legal Issues. Journal of Arabian Studies Arabia, the Gulf, and the Red Sea, Vol. 3 No. 1. 2013, p.36-52.

FAZAL, F. The urban development in Dubai: A descriptive analysis. 2008. 28f. Dissertação (Mestrado em crescimento econômico) - Departamento de economia, Universidade de Ekonomikum, Uppsala, 2008.

GARDNER, Andrew; NAGY, Sharon. Introduction: New ethnographic fieldwork among migrants, residents and citizens in the Arab States of the Gulf. City \& Society, v. 20, n. 1, p. 1-4, 2008.

GHAEMI, H. Building Towers, Cheating Workers: Exploitation of Migrant Construction Workers in the United Arab Emirates. Desenvolvida por Human Rights Watch. Disponível em:<https://www.hrw.org/report/2006/11/11/building-towers-cheating-workers/exploitation-migrantconstruction-workers-united>. Acesso em: 4 de março de 2018.

GIBLING, C. The construction process and post construction impacts of the palm Jumeirah in Dubai, United Arab Emirates. Proto, Memorial University, mar 2013. Caderno de Coastal and Ocean Engineering, p130.

GILDROY, C., et al. What is Neighborhood Planning? 2008. Disponível em: $<$ http://cityofchelan.us/planning/pdf/Neighorhood_Plan/what_is_neighborhood_planning.pdf $>$. Acesso em 09 de junho de 2014.

GROBER, U. Deep Roots: A Conceptual History of "sustainable Development" (Nachhaltigkeit). Discussion papers, Wissenschaftszentrum Berlin für Sozialforschung. Berlin: WZB, 2007.

HELLEBRAND, S. et al. Case study design of palm island No. 1, TERRA et Aqua, 2004.

HOPKINS, C. Dubai pilot project: 'Reef Systems' at the Palm Jumeirah. [online] Test report 19 pp., Aquamarine Advisers, Åstorp, Sweden. 2007. Disponível em: <https://fac.arch.hku.hk/asiancities-research/wpcontent/uploads/dubai_pilot_project.pdf>. Acesso em: 2 de janeiro de 2020.

INTERNATIONAL PANEL ON CLIMATE CHANGE - IPCC. The physical science basis. Contribuição do grupo de trabalho I para o quarto relatório de avaliação do Painel Intergovernamental sobre Mudança Climática. Cambridge University Press, Cambridge, Reino Unido e Nova lorque, NY, EUA. v. 996, 2007. p. 2007. Disponível em: <www.ipcc.ch/report/ar4/>. Acesso em: 17/03/2019.

JABAREEN, Y. A new conceptual framework for sustainable development. Environ. Dev. Sustain., v. 10, n. 2, 2008, p. 179-192.

KHALAF, S. Culture of the United Arab Emirates. Encyclopedia of Countries and Their Cultures 
(Macmillan References). New York, Vol. 4, 2001, p. 2325-2331.

KHAMIS J. How young emirates balance traditional and modern value. Notícias de Golfe. Dubai, n. 1298, p 4- 5, 5 jun 2017.

KUHLMAN. T; FARRINGTON, J. What is Sustainability? Sustainable Future. Issue 2, 2010, p. 3436-3448.

LEE, June J.H; GUADAGNO, Lorenzo. Migrants and Cities: New Partnerships to Manage Mobility. Genebra: IOM, 2015. 194p. (Relatório Mundial de Migração).

LOOK UP [For the Real Estate Investor]. Palm Jumeirah Special Report. Site eletrônico. 2015. Disponível em: <https://lookup.ae/project-profile/63/palm-jumeirah>.

MANGOR, K. et al. Shoreline Management of the Dubai Coast. PIANC-COPEDEC VII 2008: Seventh International Conference on Coastal and Port Engineering in Developing Countries, ResearchGate, Dubai, UAE, No: M-15. 2008.

MANSOUR, A. Population Imbalance as a Public Policy Problem in United Arab Emirates. In: Adjusting to a World in Motion: Trends in Global Migration and Migration Policy, Edition: 1, Chapter: 14, Publisher: Oxford University Press, 2015.

; ELSHAHIN, A. Manpower Emaratisation in the United Arab Emirates Federal Government: An Exploratory Study from the Perspective of Civil Service Leadership. Asia Pacific Journal of Public Administration. V. 30. 2014, p. 83-95. 10.1080/23276665.2008.10779344.

MUNDA, G. NIJKAMP, P. RIETVELD, P. A Qualitative multicriteria valuation for environmental management. The Trans disciplinary Journal of the International Society for Ecological Economics (ISEE), v. 10, n. 2, p. 97- 112, 1994.

NASA - National Aeronautics and Space Administration. Durrat Al Bahrain, Persian Gulf. Earth observatory. Disponível em < https://earthobservatory.nasa.gov/images/7040/palm-islands-dubai >. Acesso em: 07/06/2017.

NURSE, K. (2006), Culture as the Fourth Pillar of Sustainable Development, 2006 [online], Commonwealth Secretariat Malborough House Pall Mall London, Disponível em: <http://www.fao.org/sard/common/ecg/2785/en/Cultureas4thPil larSD.pdf >.

PACKALEN, S. Culture and sustainability, Corporate Social Responsibility and Environmental Management Corp. Soc. Responsib.Environ. Mgmt, Vol. 17, 2010, p 118-121.

PATNAIK, A.; PATNAIK, S. Fibers to Smart Textiles, Advances in Manufacturing, Technologies, and Applications, 1st ed., CRC Press, Boca Raton. 2019.

PORTMAN, Michelle Eva. Detached Islands: Artificial Islands as adaptation challenges in the making. DIE ERDE-Journal of the Geographical Society of Berlin, v. 150, n. 3, p. 158-168, 2019. DOI:10.12854/erde-2019-430.

ROB E DE JOG et al. Execution Methodology for Reclamation Works Palm Island 1, TERRA et Aqua, Setembro/2003. 
SABBAN, R. Dependence of the Local and Dependence of the Foreign: The UAE Family, Domestic Service, and a Precarious Future. Asian Migrant Workers in the Arab Gulf States. 2019, p. 103124. DOI: https://doi.org/10.1163/9789004395404_008.

SALAHUDDIN, B. The marine environmental impacts of artificial island construction Dubai, UAE. 2006. 96 f. Dissertação (Mestrado em Gestão Ambiental) - Faculdade de Meio Ambiente e Ciências da Terra, Universidade de Duke, Durham, 2006.

SANTOS, Lucas Quio dos. A cidade global na obra de Saskia Sassen. 2016. Trabalho de conclusão de curso (bacharelado - Ciências Sociais) - Universidade Estadual Paulista Júlio de Mesquita Filho, Faculdade de Ciências e Letras (Campus de Araraquara), 2016. Disponível em: <http://hdl.handle.net/11449/149268>.

SÖNMEZ, Sevil et al. Human rights and health disparities for migrant workers in the UAE. Health Hum Rights, v. 13, n. 2, p. E17-35, 2011.

TINTAWI, G. Terraforming: Cities from scratch. 2009. 184 f. Dissertação (Mestrado em arquitetura e cultura urbana). Faculdade de Arquitetura, Universidade Politécnica da Catalunha, Barcelona, 2009.

MALEK, C. Climate change and rising seas 'could spell disaster' for UAE's coastal cities. THE NATIONAL UAE. 31 de outubro de 2017. Disponível em: $<$ https://www.thenational.ae/uae/environment/climate-change-and-rising-seas-could-spell-disasterfor-uae-s-coastal-cities-1.671922>.

UMAKOSHI, E. M. Avaliação de desempenho ambiental e arquitetura paramétrica generativa para o projeto do edifício alto. 2014. 253 f. Tese (Doutorado em Tecnologia da Arquitetura) Faculdade de arquitetura e urbanismo, Universidade de São Paulo, São Paulo, 2014.

UN-HABITAT. A new strategy of sustainable neighbourhood planning: Five Principles, Discussion Note 3, Urban Planning. 2014 [online], Disponível em: <https://unhabitat.org/wpcontent/uploads/2014/05/5-Principles web.pdf>.

VAN LAVIEREN, $\mathrm{H}$. et al. Managing the growing impacts of development on fragile coastal and marine ecosystems: Lessons from the Gulf. A policy report UNU-INWEH, Hamilton, ON, Canada, United Nations University. 2011. 